\title{
Analysis of the Level of the Teacher Efficacy of Beginning Agriculture Teachers in Eswatini
}

\author{
Mpendulo Mathenjwa ${ }^{1} \&$ Marietta. P. Dlamini ${ }^{1}$ \\ ${ }^{1}$ Department of Agricultural Education and Extension, Faculty of Agriculture, The University of Eswatini, \\ Kingdom of Eswatini \\ Correspondence: Mpendulo Mathenjwa, Department of Agricultural Education and Extension, Faculty of \\ Agriculture, The University of Eswatini, Kingdom of Eswatini. E-mail: mpmatsenjwa@uniswa.sz, mper@uniswa.sz
}

Received: April 2, 2020; Accepted: April 13, 2020; Published: June 9, 2020

\begin{abstract}
Over the past decade, researchers continually emphasized the role of teacher efficacy in teaching effectiveness. A descriptive survey was used to investigate the level of teacher efficacy of beginning agriculture teachers in Eswatini. The population of the study were senior secondary school beginning agriculture teachers in Eswatini. The study is a census, involving all senior secondary school agriculture teachers who had up to five years of agriculture teaching experience. 161 agriculture teachers participated in the study. Data were collected using a self-administered modified Teachers' Self-Efficacy Scale (TSES) with a .92 reliability coefficient. The data were analysed using descriptive and inferential statistics. Beginning agriculture teachers were moderately efficacious in classroom management, instructional strategies and student engagement. Gender, subject specialization and affiliation to professional development bodies accounted for significant differences in teacher efficacy on selected agriculture teaching tasks. Beginning agriculture teachers are capable of getting the desired learning outcomes from senior secondary school agriculture students as indicated by the moderate level of teacher efficacy. Preservice teacher training programmes should strengthen curriculum content on ways of engaging students.
\end{abstract}

Keywords: beginning agriculture teacher, classroom management efficacy, instructional strategies efficacy, teacher efficacy, senior secondary school, student engagement efficacy

\section{Introduction}

There is consensus among researchers and educators that any improvement in teaching and learning requires effective teaching. Meaningful progress in reforms and deliverables of any educational system requires teachers with distinct qualities. Teacher efficacy is a motivational construct influencing teacher effectiveness. The concept of teacher efficacy is based on social cognitive theory (Bandura, 2006). Teacher efficacy refers to the teachers' belief in their capabilities to organise and execute courses of action to bring about the desired students learning outcomes (Tschannen-Moran, Woolfolk-Hoy \& Hoy, 1998). Skaalvik and Skaalvik (2010) expanded teacher efficacy to involve individual teacher's belief in his or her ability to plan, organise and carry out activities required to attain educational goals. Teacher efficacy is the most powerful and influential human agency factor that determines a teacher's choices, effort levels, perseverance amidst challenges, and anxieties or confidence. Studies (Jeon, 2017; Pravirash, Samaneh \& Nader, 2012; Wangeri \& Otanga, 2014) indicate that teacher efficacy explains teacher behaviour and predicts teacher effectiveness. There is a close relationship between teacher efficacy and getting the desired learning outcomes from students.

\subsection{Theoretical Framework}

Bandura's social cognitive theory serves as a theoretical framework that focuses on the relationships among teacher's efficacy beliefs, competency, performance, and the learning environment (Bandura, 2006). The social cognitive theory (SCT) explains that teachers' perceptions of their teaching competence reflect the use of judgement of teaching effectiveness that is conditioned by teaching experience, previous students' outcomes and social environment. According to the SCT, teacher efficacy is conditioned in a triadic and reciprocal interaction. Tschannen-Moran, Woolfolk Hoy and Hoy (1998) suggested an integrated model that reveals the cyclical nature of teacher efficacy. In the integrated model, the sources of efficacy information, the cognitive process of the teacher, analysis of the teaching task and assessment of personal teaching competence, teacher efficacy, and performance are interrelated reciprocally. According to the model, high efficacy leads to a high level of effort and persistence in a teacher. This causes high performance which produces high teacher efficacy. Teachers with a low level of 
efficacy are more likely to give up when faced with difficulties. This leads to low performance among teachers with low teaching efficacy scores.

Sources of efficacy information for the teacher include mastery experiences, vicarious experiences, verbal persuasion and physiological states which are cognitively processed in relation to the analysis of the teaching task. The scope and diversity of the sources of efficacy information vary during teacher career stages from pre-service to in-service and teaching experience (Wolf, 2011; Shaughnessy, 2004). Fessler and Christensen (1992) describe teacher's career cycle into eight stages based on self-reported characteristics of teachers on variables such as enthusiasm, interactive teaching skills, attitudes towards students and teaching, and attitudes towards the teaching profession. Ushers and Pajeres (2008) asserted that the influence of each source of efficacy information varies according to contextual factors such as gender, age and domain-functioning. Gist and Mitchell (1992) identified three assessment processes that combine with the four sources of efficacy information and ultimately influence performance outcomes. The assessment processes include analysis of task requirements, attributional analysis of experience, and assessment of personal and situational resources or constraints.

\subsection{Nature of Teacher Efficacy}

Teacher efficacy is context-specific (Tschannen-Moran, Woolfolk Hoy, \& Hoy, 1998) owing to Bandura (2006) call of domain functioning specificity of teacher efficacy instruments. Several studies have been done on factors that influence teacher efficacy. Most studies examined the relationships between teacher efficacy and background characteristics of teachers. Beginning teachers offer an excellent entry point to study teacher efficacy levels because they just finished pre-service with high levels of efficacy (Harverback \& Parault, 2008) which interact with the reality of school-based variables (Woolfolk Hoy \& Burke-Spero, 2005) which can dampen or inflate teacher efficacy levels.

To date, few studies have examined the level of teacher efficacy of beginning agriculture teachers in Eswatini. Unsal, Korkmaz and Percin (2016) observed that most studies on teacher efficacy focus on pre-service teachers. This paper partially addresses the gap in the research by reporting teacher efficacy levels of beginning agriculture teachers at Senior Secondary schools in the Kingdom of Eswatini. Despite the high teacher efficacy accrued due to the successful completion of the pre-service teacher programme, beginning teachers face different contextual factors in various placement schools. The diverse contextual factors in placement schools cause beginning teachers to recalibrate their teacher efficacy to low levels in an attempt to avoid self-assessment of failure (TschannenMoran \& Woolfolk Hoy, 2007). Studies (Woolfolk Hoy \& Burke-Spero, 2005; Pendergast, Garvis \& Keogh, 2011) concurred that teacher efficacy is changeable, emphasizing that attention to changing efficacy beliefs in early career stages is desirable because, once established, experienced teachers' efficacy seem resistant to change. Furthermore, the poor academic performance of students in agriculture in the national examinations in Eswatini suggests that teacher efficacy of agriculture teachers had to be examined.

\subsection{Purposes of the Study}

The purposes of the study were to examine the level of teacher efficacy of beginning agriculture teachers at Senior Secondary schools in Eswatini. Further, the study sought to compare the level of teacher efficacy of beginning agriculture teachers based on demographic characteristics.

\subsection{Research Questions}

The study sought to answer the following research questions:

1. What are the levels of teacher efficacy of beginning agriculture teachers?

2. Are there any significant differences in the teacher efficacy of beginning agriculture teachers based on;

a) Gender,

b) Subject specialization, and

\section{Methods}

c) Affiliation to Swaziland Agriculture Teachers' Association (SATA)?

The research design employed in the study is a descriptive survey. The descriptive survey was chosen because of ease at which the researcher could obtain participants' opinions (Polit \& Beck, 2004) and it seeks to describe the past or current state of a group (Karasar, 2000). The study is a cross-sectional descriptive survey on the level of teacher efficacy of beginning agriculture teachers at Senior Secondary school in Eswatini.

\subsection{Population}

The population of the study consisted of beginning agriculture teachers teaching at Senior Secondary school. A beginning teacher is a teacher with fewer than five years of teaching experience. In Eswatini a teacher is eligible 
to contest any administrative position within the schooling systems after serving a minimum of five years (Ministry of Education and Training, 2016). The survey was administered in October to December in the 2016 calendar year to all eligible beginning Agriculture teachers who had less than five years of agriculture teaching experience at senior secondary school. The Ministry of Education and Training Directorate granted the ethical clearance to conduct the study on senior secondary school agriculture teachers. The participation of beginning agriculture teachers was voluntary and informed consent was granted before the administration of the survey.

\subsection{Sampling Procedures}

The sampling frame of the study was obtained from the Schools Agriculture Department and cross-checked against the calendars of the University of Eswatini graduation records. It is a census survey study, involving all agricultural education graduates from the University of Eswatini who completed during the calendar years of 2012 to 2015. Based on the sampling frame, 179 Senior Secondary school agriculture were eligible to participate and only 161 participated in the study.

Beginning agriculture teacher participants had an average age of 28 years old, teaching experience of 3 years and taught an average class size of 41pupils. Table 1 presents the background information of the participants of the study.

Table 1. Background Characteristics of Beginning Agriculture Teachers in Eswatini

\begin{tabular}{llll}
\hline Background characteristics & & $\mathbf{N}$ & $\mathbf{\%}$ \\
\hline Gender & Female & 51 & 31.68 \\
Subject Specialization & Male & 110 & 68.32 \\
& No & 102 & 63.35 \\
\multirow{2}{*}{ Affiliation to SATA } & Yes & 59 & 36.65 \\
& No & 92 & 57.14 \\
& Yes & 69 & 42.86 \\
\hline
\end{tabular}

\subsection{Instrumentation}

The study used the Teachers' Self Efficacy Scale (TSES) developed by Tschannen-Moran and Woolfolk (2001) and adapted to the context of teaching agriculture at Senior Secondary school in Eswatini. Haram (2018) opined that the 24-item of the TSES were better suited to measure personal teaching efficacy. Bandura (2006) advocated for the development of teacher efficacy scales that are sensitive to the specificity of the task and domain functioning. The TSES was modified by two focus group discussions involving agricultural education graduates linked with teaching, supervision and monitoring of senior secondary school agriculture. The TSES has three dimensions of efficacy namely: instructional strategies (IS), classroom management (CM), and student engagement (SE) which "represent the richness of teachers' work lives and the requirements of good teaching" (Tschannen-Moran and Woolfolk Hoy 2001). The modified TSES had 29 items on a nine-point Likert-type capability rating scale to allow greater differentiation among responses. The teachers' capability was assessed along a 9-point continuum with anchors at $1=$ no capability, $3=$ very little capability, $5=$ little capability, $7=$ moderate capability, and $9=$ a great deal of capability. The scale was designed to measure IS, CM and SE dimensions of agriculture teacher efficacy. The reliability coefficients of the teacher efficacy scale of the study were: .91 for classroom management domain; .93 for instructional strategies efficacy; .91 for student engagement efficacy and .92 for the overall agriculture teacher efficacy scale. Background information of the participants included gender, subject specialization and affiliation to Swaziland Agriculture Teachers' Association were also solicited.

\subsection{Data Analysis}

SPSS 20.0 statistical software was used to analyse the data. The data followed normal distribution thus parametric statistics which included: descriptive statistics, independent $t$-tests and analysis of variance (ANOVA) were used for data analysis. Based on prior research (Wolf, 2011; Knap, 2013; Sangueza, 2010; Moalasi \& Forcheh, 2015) the item responses for the modified TSES were combined into the following categories $1.00-3.44,3.45-5.44$, $5.45-8.44$ and $8.45-9.00$ and interpreted as very low, low, moderate and high teacher efficacy, respectively. Standard deviation was used to describe the variability in individual teacher efficacy scores. An alpha level of .005 $(5 \%)$ was set apriori and calculated $p$-value less than .005 $(<.005)$ indicated significant differences in group means. 


\section{Findings}

\subsection{What are the Levels of Teacher Efficacy of Beginning Agriculture Teachers?}

The findings of the study indicate that beginning agriculture teachers were moderately efficacious in all three dimensions of teacher efficacy as shown in Table 2. The mean agriculture teacher efficacy scores in classroom management, instructional strategies and student engagement were $6.78 ; 6.77$ and 6.52 respectively. Regarding specific agriculture teaching tasks, teachers reported the highest capability belief $(\mathrm{M}=7.45 ; \mathrm{SD}=1.16)$ in providing alternative explanations when learners are confused. Low teacher efficacy $(\mathrm{M}=5.32 ; \mathrm{SD}=2.29)$ was reported in assisting learners' market produce, though individual teachers' capability beliefs varied greatly from the mean score.

Table 2. Means and Standard Deviations of Beginning Agriculture Teacher Efficacy

\begin{tabular}{|c|c|c|}
\hline Item & M & SD \\
\hline 1. Get my learners to observe safety rules during subject practicals & 7.34 & 1.62 \\
\hline 2. Supervise the learners in animal production & 7.14 & 1.82 \\
\hline 3.Manage all activities related to crop production & 7.04 & 1.72 \\
\hline 4. Get my learners to adhere to classroom rules & 7.01 & 1.64 \\
\hline 5. Control disruptive behaviour in my classroom & 6.91 & 1.66 \\
\hline 6. Establish routines to keep activities running smoothly & 6.64 & 1.86 \\
\hline 7. Respond well to defiant students & 6.37 & 1.75 \\
\hline 8. Get through to most difficult learners in the class & 5.86 & 1.84 \\
\hline Teacher efficacy on classroom management average & 6.78 & 1.16 \\
\hline 1. Provide alternative explanations when my learners are confused & 7.45 & 1.60 \\
\hline 2. Respond to difficult questions from learners & 7.42 & 1.71 \\
\hline 3. Develop questions that are appropriate for my learners & 7.26 & 1.57 \\
\hline 4. Assess the practical work by adhering to the syllabus criterion & 6.96 & 1.85 \\
\hline 5. Use different teaching methods in my classes & 6.90 & 1.81 \\
\hline 6. Integrate current advances in agriculture & 6.76 & 4.24 \\
\hline 7. Link curriculum instruction with learners' home practices & 6.72 & 2.01 \\
\hline 8. Simplify the curriculum for my learners & 6.65 & 1.85 \\
\hline 9. Gauge learners' comprehension of what I have taught & 6.58 & 1.79 \\
\hline 10. Use a variety of assessment strategies & 6.57 & 1.84 \\
\hline 11. Teach learners to think critically & 6.42 & 2.02 \\
\hline 12. Provide appropriate challenges for capable learners & 6.35 & 1.84 \\
\hline 13. Teach my learners at all levels of cognition & 6.05 & 1.88 \\
\hline Teacher efficacy on instructional strategies average & 6.77 & 1.20 \\
\hline 1. Help students value learning agriculture & 7.42 & 1.80 \\
\hline 2. Motivate learners to show interest in their school work & 7.01 & 1.85 \\
\hline 3. Supervise investigatory projects for learners & 6.91 & 2.11 \\
\hline 4. Get my learners to actively participate in the class & 6.61 & 1.98 \\
\hline 5. Manage the tools for the department & 6.58 & 1.98 \\
\hline 5. Finishing the syllabus within the set deadline & 6.55 & 2.27 \\
\hline 6. Identify teachable moments during agriculture practical activities & 6.38 & 1.94 \\
\hline 7. Make timely entries to the learners' academic portfolios & 5.88 & 1.97 \\
\hline 8. Assist learners to market their produce & 5.32 & 2.29 \\
\hline Teacher efficacy on student engagement average & 6.52 & 1.38 \\
\hline Overall teacher efficacy & 6.70 & 1.09 \\
\hline
\end{tabular}

3.2 Are there any Significant Differences in Teacher Efficacy of Beginning Agriculture Teachers Based on: Gender, Subject Specialization and Affiliation to SATA

\subsubsection{Gender}

Based on gender, significant differences in teacher efficacy among beginning agriculture teachers were noted on ensuring students observe safety rules during practicals $(t$ value $=2.659 ; \mathrm{p}=009)$ and developing questions that are appropriate for learners $(t$ value $=2.041 ; \mathrm{p}=043)$. Female beginning agriculture teachers had a significantly higher level of 
teacher efficacy relative to their male counterparts in ensuring students observe safety rules during practicals and developing appropriate questions for learners.

\subsubsection{Subject Specialization}

Beginning agriculture teachers who did not specialize (taught agriculture and other subjects) were significantly different $(t$ value $=2.127 ; \mathrm{p}=035)$ in their capability belief in gauging the comprehension of students on what they have been taught. Beginning agriculture teachers who taught agriculture only at Senior Secondary had lower confidence in their capability to gauge the comprehension of students on what has been taught compared to their counterparts who taught agriculture and other subjects offered in the school curriculum. No significant differences existed on the efficacy mean scores on classroom management, instructional strategies and student engagement of beginning agriculture teachers.

\subsubsection{Affiliation to SATA}

The affiliation status of beginning agriculture teachers to SATA had significant differences $(t$ value $=2.087 ; \mathrm{p}=.038)$ in the capability beliefs scores in teaching students at all levels of cognition. Teachers who were not affiliated with SATA had a higher efficacy mean score in teaching agriculture students at all levels of cognition.

The $t$-test analysis revealed no significant differences at $\mathrm{p}<.05$ for all the three dimensions of teacher efficacy against the independent variables of gender, subject specialisation and affiliation to subject-based teacher association.

Table 3. T-test Results between Beginning Agriculture Teacher Efficacy Scores and Selected Background Characteristics

\begin{tabular}{|c|c|c|c|c|c|}
\hline Teaching task & Background characte & stics & Mean & t-value & $\mathbf{P}$ \\
\hline 1. Ensuring students observe safety rules & Gender & Female & 7.82 & 2.659 & $.009 * * *$ \\
\hline during practicals & & Male & 7.10 & & \\
\hline 2. Developing questions that are & Gender & Female & 7.62 & 2.041 & $.043^{* *}$ \\
\hline appropriate for learners & & Male & 7.09 & & \\
\hline 3. Gauging comprehension of students on & Subject specialization & No & 6.80 & 2.127 & $.035 * *$ \\
\hline what has been taught & & Yes & 6.18 & & \\
\hline 4. Teaching students at all levels of & Affiliation to SATA & No & 6.31 & 2.087 & $.038 * *$ \\
\hline cognition & & Yes & 5.69 & & \\
\hline
\end{tabular}

\section{Discussion}

\subsection{Level of Teacher Efficacy of Beginning Agriculture Teachers}

The results indicate that beginning agriculture teachers are moderately efficacious in all three dimensions of teacher efficacy namely classroom management, instructional strategies and student engagement. Beginning agriculture teachers have moderate capability belief to organise and execute courses of action to bring about the desired students learning outcomes. The level of teacher efficacy of beginning agriculture teachers is consistent with studies (Jaggernauth \& Jameson-Charles, 2015; Eslami \& Fatahi, 2008; Swafford, 2013; Selbie, 2015) which uncovered moderate teacher efficacy among in-service English and Agriculture teachers. Direct comparison of teacher efficacy scores is reported with extreme caution due to the possibility that survey responses may reflect cultural biases (King, Murray, Solomon \& Tandon, 2004; Jeon, 2017). According to Sridhar and Badiei (2008) teacher efficacy research centres on the effects of teacher efficacy on two categories of teachers namely high teacher efficacy and low teacher efficacy. Based on the moderate level of teacher efficacy of beginning agriculture teachers, positive teacher behaviour and effectiveness in teaching agriculture can be predicted at senior secondary schools in Eswatini.

\subsection{Differences in Teacher Efficacy of Beginning Agriculture Teachers Related to Background Characteristics}

Based on social cognitive theory, Bandura (2006) posited that teacher efficacy is a triadic reciprocal interaction between personal and environmental factors. The study investigated differences in teacher efficacy levels of beginning agriculture teachers based on background characteristics which included gender, subject specialization and affiliation to professional development bodies. The selected background characteristics did not have any significant differences in the capability beliefs of beginning agriculture teachers to manage classrooms, choose instructional strategies and engage students. The findings of non-significant differences in teacher efficacy contradict findings (Klassen \& Chiu, 2010; Shaukat \& Iqbal, 2012; Gkolia, Dimistrios \& Koustelios, 2016; Lesha, 
2017) that male teachers were significantly better than female teachers in classroom management and student engagement. However, the findings of the study revealed female agriculture teachers were significantly better in their capability beliefs in ensuring students observe safety rules during practicals and developing questions that are appropriate for learners. This evidence supports (Sridhar \& Badiei, 2008; Dehghani, Sani, Pakmehr \& Malekzadeh, 2011; Sarfo, Amankwah \& Konin, 2015; Kumar, Verma \& Kiran, 2017) conclusion of female teacher efficacy higher than male teacher efficacy.

Based on subject specialization, beginning agriculture teachers did not differ significantly in classroom management, instructional strategies and student engagement. This finding augments Khezerlou (2013) conclusion that teaching loads associated with burnout have no significant differences in teacher efficacy. However, significant differences were only noted in capability beliefs on gauging students' comprehension of what has been taught. Beginning agriculture teachers who taught several subjects in school had a superior capability belief in gauging students' comprehension than agriculture teachers who taught agriculture only.

Affiliating to the association of agriculture teachers in Eswatini had no significant differences in the capability beliefs of beginning agriculture teachers to manage classrooms, choosing instructional strategies for learners and engaging students. The results contradict studies (Thompson, 2016; Heaton, 2013) that affiliating to a professional development association strengthens teacher efficacy. The findings on teachers who were not affiliated to any professional development association having a significantly higher capability belief in teaching students in all cognition levels support a conclusion of Nolan (2009) that affiliation to professional development communities is negatively correlated to teacher efficacy.

\section{Conclusions}

The purpose of the study was to assess the level of teacher efficacy of beginning agriculture teachers at Senior Secondary schools in Eswatini. Beginning agriculture teachers in Eswatini were efficacious in all the domains of teacher efficacy which included classroom management, choosing appropriate instructional strategies and engaging students. Demographic characteristics did not yield significant differences in the three domains of teacher efficacy.

\section{Recommendations}

Based on the findings of the study, school administrators should sustain the efficacy beliefs of agriculture teachers by facilitating a positive climate in schools. There is a need for agriculture pre-service teacher training programmes to put more emphasis on pedagogy to engage students in classrooms. Further research should be conducted on malleability teacher efficacy and factors influencing teacher efficacy in schools

\section{Implications}

The study provides insights on potential content areas of pre-service teacher training and in-service training programmes that can be strengthened especially where agriculture teachers reported low capability beliefs.

\section{References}

Bandura, A. (2006). Guide for constructing self-efficacy scales. In F. Pajares \& T. Urdan (Eds.), Adolescence and education: Self-efficacy and adolescence, 5. Greenwich, CT: Information Age.

Dehghani, M., Sani, H. J., Pakmehr, H., \& Malekzadeh, A. (2011). Relationship between students critical thinking and self-efficacy beliefs in Ferdowsi University of Mashhad, Iran, Procedia Social and Behavioural Sciences, 15, 2952-2955. https://doi.org/10.1016/j.sbspro.2011.04.221

Eslami, Z. R., \& Fatahi, A. (2008). Teachers' sense of self-efficacy, English proficiency and instructional strategies: A study of Non-native EFL teachers in Iran. TESL-EJ, 11(4), 1-19.

Fessler, R., \& Christensen, J. (1992). The teacher career cycle. In the teacher career cycle: Understanding and guiding professional development of teachers, ed. R.Boston: Allyn and Bacon

Gist, M., \& Mitchell, T. (1992). Self-efficacy: A Theoretical Analysis of its Determinants and Malleability. The Academy of Management Review, 17(2), 183-211. https://doi.org/10.2307/258770

Gkolia, A., Dimistrios, B. A., \& Koustelios, A. (2016). Background characteristics as predictors of Greek teachers' self-efficacy. International Journal of Educational Management, 30(3), 460-472. https://doi.org/10.1108/IJEM-03-2014-0040

Haram, J. (2018). Teacher efficacy research in the global context. Korea University. Retrieved from https://www.researchgate.net/publication/322266142

Haverback, H. R., \& Parault, S. J. (2008). Pre-service reading teacher efficacy and tutoring. A Review: Educational 
Psychology Review, 20(3), 237-255. https://doi.org/10.1007/s10648-008-9077-4

Heaton, M. (2013). An examination of the relationship between professional learning community variables and teacher self-efficacy. Electronic Theses and Dissertations, 5038.

Jaggernauth, S. J., \& Jameson-Charles, M. (2015). Initial teacher efficacy of in-service secondary teachers in Trinidad and Tobago. Caribbean Curriculum, 23, 23-28.

Jeon, H. (2017). Teacher efficacy research in a global context. Center of social cohesion Education, Korea University. https://doi.org/10.4324/9781315710068-27

Karasar, N. (2000). Scientific research methods-Term, scopes, Techniques. Ankara: Nobel Publication.

Khezerlou, E. (2013). Teacher self-efficacy as a predictor of job burnout among Iranian and Turkish EFL teachers. Procedia- Social and Behavioural Sciences, 70, 1186-1194. https://doi.org/10.1016/j.sbspro.2013.01.175

King, G., Murray, C., Salomon, J., \& Tandon, A. (2004). Enhancing the validity and cross-cultural comparability of measurement in survey research. American Political Science Review, 98, 191-207. https://doi.org/10.1017/S000305540400108X

Klassen, R. M., \& Chiu, M. M. (2010). Effects of teachers' self-efficacy and job satisfaction: Teacher gender, years of experience and job stress. Journal of Educational Psychology, 102(3), 741-756. https://doi.org/10.1037/a0019237

Knap, A. K. (2013). A Study of Secondary Science Teacher Efficacy and Level of Constructivist Instructional Practice Implementation in West Virginia Science Classrooms. Theses, Dissertations and Capstones, Paper 472.

Kumar, R. A., Verma, L., \& Kiran, N. (2017). Self-Efficacy among higher secondary schoolteachers: Empirical study. The Online Journal of New Horizons in Education, 7(30), 53-57.

Lesha, J. (2017). Gender differences in primary school teachers' self-efficacy beliefs. European Journal of Educational Studies, 3(10), 730-740.

Ministry of Education \& Training. (2015). The Swaziland Education for ALL Review Report, 2000-2015. Retrieved from https://planipolis.iiep.unesco.org/en/2015/swaziland-education-all-review-report-20002015-6140

Moalosi, W.T. S., \& Forcheh, N. (2015). Self-Efficacy levels and gender differentials among teacher trainees in colleges of education in Botswana. Journal of Education and Learning, 4(3), 1-13. https://doi.org/10.5539/jel.v4n3p1

Nolan, D. (2009). A study of the relationship of teacher self-efficacy and the impact of professional learning community as an organisational structure. Doctoral dissertation submitted at the Louisiana State University and Agricultural and Mechanical College.

Parivash, J., Samaneh, K., \& Nader, S. (2012). The relationship among organisational climate, organisational learning and teacher efficacy. Procedia Social Behaviour Science, 47, 2212-2218. https://doi.org/10.1016/j.sbspro.2012.06.974

Pendergast, D., Garvis, S., \& Keogh, J. L. (2011). Pre-service teachers' self-efficacy beliefs: An insight into making $\begin{array}{lllll}\text { teachers. Australian Journal of Teacher Education, 36(12), 46-57. } & \text {. }\end{array}$ https://doi.org/10.14221/ajte.2011v36n12.6

Polit, D. F., \& Beck, C. T. (2004). Nursing research: Appraisal of evidence for nursing practice ( $7^{\text {th }}$ Edition). Philadelphia: Wolters Klower/Lippincott Williams \& Wilkins.

Sangueza, C. R. (2010). Pre-service elementary science teaching self-efficacy and teaching practices: A mixedmethods, dual-phase, embedded case study. UNLV theses, Dissertations, Professional Papers, and Capstones. 844.

Sarfo, F. K., Amankwah, F., Sam, F. K., \& Konin, D. (2015). Teachers' Self-efficacy Beliefs. GJDS, $12(1$ \& 2), 19-32. https://doi.org/10.4314/gjds.v12i1-2.2

Selbie, L. (2015). Examining the sources of teacher efficacy and how the context of teaching contributes to teacher efficacy. (Doctoral dissertation submitted in the Colombus State, University. Colombus, GA.

Shaughnessy, M. F. (2004). An interview with Anita Woolfolk. The educational psychology of teacher efficacy. Educational Psychology Review, 16, 153-176. https://doi.org/10.1023/B:EDPR.0000026711.15152.1f 
Shaukat, S., \& Iqbal, H. M. (2012). Teacher self-efficacy as a function of student engagement, instructional strategies and classroom management. Pakistan Journal of Social and Clinical Psychology, 9(3), 82-85.

Skaavlik, E. M., \& Skaalvik, S. (2010). Teacher self-efficacy and teacher burnout: A study of relations. Teaching and Teacher Education, 26, 1059-1069. https://doi.org/10.1016/j.tate.2009.11.001

Sridhar, Y.N., \& Badiei, H. R. (2008). Teacher Efficacy Beliefs: A Comparison of Teachers in India and Iran. Journal of the Indian Academy of Applied Psychology, 34, 81-89.

Swafford, M. R. (2013). Factors affecting teacher efficacy of beginning secondary agricultural education teachers. (Doctoral dissertation submitted to the Graduate Faculty of the Lousiana State University and Agricultural and Mechanical College).

Thompson, G. (2016). Japanese High School English Teachers' Self-Efficacy Beliefs about Teaching English. Unpublished Doctoral Dissertation submitted in the Queensland University of Technology.

Tschannen-Moran, M., \& Woolfolk Hoy, A. (2001). Teacher efficacy: Capturing Construct. Teaching and Teacher Education, 17, 783-805. https://doi.org/10.1016/S0742-051X(01)00036-1

Tschannen-Moran, M., \& Woolfolk Hoy, A. (2007). The differential antecedents of self-efficacy beliefs of novice and experienced teachers. Teaching and Teacher Education, 23, 944-956. https://doi.org/10.1016/j.tate.2006.05.003

Tschannen-Moran, M., Woolfolk Hoy, A., \& Hoy, W. K. (1998). Teacher efficacy: Its meaning and measure. Review of Educational Research, 68(2), 202-248. https://doi.org/10.3102/00346543068002202

Unsul, S., Korkmaz, K., \& Percin, S. (2016). There is a close relationship between teacher self-efficacy perceptions and in displaying a successful performance. Journal of Education and Practice, 7(24), 99-107.

Ushers, L. L. \& Pajares, F. (2008). Sources of self-efficacy in school: Critical Review of the Literature and Future Directions. Review of Educational Research, 78(4), 751-796. https://doi.org/10.3102/0034654308321456

Wangeri, T., \& Otanga, H. (2014). Sources of personal teacher efficacy and influence on teaching methods among teachers in primary schools in coast province, Kenya. Global Journal of Interdisciplinary Social science, 3, 190-195.

Wolf, K. J. (2011). Agricultural education perceived teacher self-efficacy. A descriptive study of beginning agricultural education teachers. Journal of Agricultural Education, 52(2), 163-176. https://doi.org/10.5032/jae.2011.02163

Woolfolk Hoy, A. E., \& Burke-Spero, R. (2005). Changes in teacher efficacy during the early years of teaching. A comparison of four measures. Teaching and Teacher Education, 21(4), 343-356. https://doi.org/10.1016/j.tate.2005.01.007

\section{Copyrights}

Copyright for this article is retained by the author(s), with first publication rights granted to the journal.

This is an open-access article distributed under the terms and conditions of the Creative Commons Attribution license (http://creativecommons.org/licenses/by/4.0/). 